\title{
Distribution Voltage in DC Micro-grid System based Solar PV Topologies Configuration in Sarawak, Malaysia
}

\author{
M. R. M. Sharip ${ }^{1 *}$, D. K. A. Sakawi ${ }^{1}$, D. N. Zaidel ${ }^{1}$, P.R.P Hoole ${ }^{2}$, M. H. I. \\ Saad $^{1}$, A. S. Abdullah', A. H. A. Karim ${ }^{1}$, H. H. A. Halim ${ }^{1}$, A. K. Rahman ${ }^{1}$ \\ ${ }^{1}$ Department of Electrical and Electronic Engineering, Faculty of Engineering, \\ Universiti Malaysia Sarawak, Kota Samarahan, Sarawak, 94300, MALAYSIA \\ ${ }^{2}$ Department of Electrical and Electronic Engineering, Faculty of Engineering \\ University of Peradeniya, Peradeniya 20400, SRI LANKA \\ *Corresponding Author
}

DOI: https://doi.org/10.30880/ijie.2020.12.06.010

Received 8April 2020; Accepted 4 June 2020; Available online 2 July 2020

\begin{abstract}
In the past few decade, longhouse communities in the rural area of Sarawak has been experienced the limitation of electricity supplies. Due to geographic of Sarawak, supply electricity to these rural areas from utility grid through transmission lines also will only results in many losses, the initiation of utilize solar as prime sources is favourable solution. The implementation of DC microgrid system for this area will achieved, as the solar PV system is a DC source to generate electrical supply for appliances in longhouse communities. However, the tropical climate and geographical in Sarawak such as the inconsistent solar radiation, changing temperatures, high humidity and heavy rainfall will be the main restrain to implement solar DC microgrid system. Thus, this paper proposes a comprehensive study about the voltage distribution of DC microgrid configuration in order to investigate system the reliability and efficiency. The configuration of DC micro-grid model has been designed using MATLAB Simulink and an experimental presenting the Simulink also has been developed for validation purposes. The obtained simulation and experimental results confirm that the proposed configuration of the ring system with multiple-sources is more reliable and efficient than radial system with multiple-source configuration in terms of DC voltage distribution at different buses. Thus, the proposed configuration is more reliable according to voltage distribution at each buses.
\end{abstract}

Keywords: DC microgrid, experiment, modelling, renewable energy, solar photovoltaic

\section{Introduction}

In Sarawak, the coverage of electricity is the lowest compared to other state in Malaysia. Due to the location that are remote from the electrical grid as well as the variable tropical climate in Sarawak, the community living in these rural places experienced limitation of accessibility to modern world due to the limited accessed to electricity. Therefore, diesel generator powers used for their daily electricity, however the usage of diesel generator cause a high electricity production cost and diesel transportation issues [1]. Other than that, different 